\title{
Analysis of Microbial Communities and Pathogen Detection in Domestic Sewage Using Metagenomic Sequencing
}

\author{
Muhammad Yasir 1,2 \\ 1 Special Infectious Agents Unit, King Fahd Medical Research Center, King Abdulaziz University, \\ Jeddah 21589, Saudi Arabia; yasirkhattak.mrl@gmail.com or yamuhammad@kau.edu.sa; \\ Tel.: +966-563202241 \\ 2 Medical Laboratory Technology Department, Faculty of Applied Medical Sciences, \\ King Abdulaziz University, Jeddah 21589, Saudi Arabia
}

Citation: Yasir, M. Analysis of Microbial Communities and Pathogen Detection in Domestic Sewage Using Metagenomic Sequencing. Diversity 2021, 13, 6 . https://dx.doi.org/10.3390/d13 010006

Received: 13 November 2020 Accepted: 22 December 2020 Published: 25 December 2020

Publisher's Note: MDPI stays neutral with regard to jurisdictional claims in published maps and institutional affiliations.

Copyright: () 2020 by the author. Licensee MDPI, Basel, Switzerland. This article is an open access article distributed under the terms and conditions of the Creative Commons Attribution (CC BY) license (https: / / creativecommons.org/ licenses/by/4.0/).

\begin{abstract}
Wastewater contains diverse microbes, and regular microbiological screening at wastewater treatment plants is essential for monitoring the wastewater treatment and protecting environmental health. In this study, a metagenomic approach was used to characterize the microbial communities in the influent and effluent of a conventional domestic sewage treatment plant in the metropolitan city of Jeddah. Bacteria were the prevalent type of microbe in both the influent and effluent, whereas archaea and viruses were each detected at $<1 \%$ abundance. Greater diversity was observed in effluent bacterial populations compared with influent, despite containing similar major taxa. These taxa consisted primarily of Proteobacteria, followed by Bacteroidetes and Firmicutes. Metagenomic analysis provided broad profiles of 87 pathogenic/opportunistic bacteria belonging to 47 distinct genera in the domestic sewage samples, with most having $<1 \%$ abundance. The archaea community included 20 methanogenic genera. The virus-associated sequences were classified mainly into the families Myoviridae, Siphoviridae, and Podoviridae. Genes related to resistance to antibiotics and toxic compounds, gram-negative cell wall components, and flagellar motility in prokaryotes identified in metagenomes from both types of samples. This study provides a comprehensive understanding of microbial communities in influent and effluent samples of a conventional domestic sewage treatment plant and suggests that metagenomic analysis is a feasible approach for microbiological monitoring of wastewater treatment.
\end{abstract}

Keywords: sewage; metagenomic; bacteria; pathogens; archaea; virus

\section{Introduction}

The exponential growth of the world's population along with urbanization and socioeconomic development has resulted in the generation of billions of tons of solid waste and wastewater every year [1]. About $80 \%$ of the wastewater flows back into the ecosystem without being treated or reused (https: / / www.unwater.org/water-facts/quality-andwastewater), carrying a wide variety of contaminants, including microorganisms, heavy metals, and organic as well as inorganic compounds [2-4]. The natural water quality is adversely affected by sewage discharge because it drastically changes the physicochemical as well as microbial composition of freshwater sources [2,4-6]. Various types of wastewater treatment plants (WWTPs) are used in different countries to improve the physicochemical and microbiological discharge quality of wastewater effluent $[2,3,7,8]$. WWTPs employs a series of processes, namely, preliminary treatment, secondary treatment, secondary clarification, tertiary treatment, disinfection, sludge processing etc [9]. Microbial community composition and diversity in treated water is shaped by both operating conditions and influent characteristics [3,9]. The core bacterial community in WWTPs is mainly comprised of Proteobacteria, classified as $\beta$-proteobacteria followed by $\gamma$-proteobacteria and genera of Dokdonella, and Zoogloea [3,10]. Nitrospira is dominantly found in activated sludge, and Arcobacter taxa are highly abundant in raw sewage [3,11]. A $16 \mathrm{~S}$ amplicon study of 
14 urban WWTPs in four countries (United States, Canada, China, and Singapore) identified the bacterial genera Arcobacter, Aeromonas, Corynebacterium, and Clostridium in the majority of activated sludge, influent, and effluent samples [8].

Metagenomic analysis of municipal WWTPs integrating conventional and membrane bioreactor revealed Pseudomonas, Bacteroides, Aeromonas, Prevotella, and Cloacibacterium dominated the influent samples [12]. But variation was observed in the bacterial communities between membrane bioreactor treated and conventional settling tank treated effluents. Taxa of Pseudomonas, Acinetobacter, Varivorax, Comamonas, Thermomonas, and Acidovorax were mainly found in post-membrane bioreactor treated effluent, while Cloacibacterium, Pseudomonas, Aeromonas, Arcobacter, Flavobacterium, Bacteroides, and Acinetobacter identified mainly in secondary settling tank treated effluent. Tonga et al. identified Arcobacter as a most dominant bacteria commonly in the influents of Six WWTPs with three different treatment processes followed by Bacteroides, Acinetobacter, Macellibacteroides, Pseudomonas, Aeromonas, and Trichococcus [13]. The abundance of Pseudomonas, Aeromonas, and Acinetobacter decreased in most of the effluents from different treatment process of WTTPs [13]. Overall, microbial diversity of treated water changed with the capacity of the WWTPs, influent composition, and affected by the environmental factors, mainly with temperature changes $[2,9,14]$.

Among the bacteria in municipal wastewater, pathogenic bacteria are of particular concern [15]. Several studies reported the abundance and diversity of Acinetobacter spp., Clostridium perfringens, Escherichia coli, Pseudomonas aeruginosa, Salmonella spp. Legionella pneumophila, Mycobacterium tuberculosis, Staphylococcus aureus, and Vibrio cholerae in municipal sewage $[8,15,16]$. Shannon et al. detected commonly reported microbial pathogens at five different stages of treatment in a WWTP in Canada [17]. Moreover, urban wastewater has been identified as a significant source of antibiotic-resistant bacteria and antimicrobial resistance genes [12]. Pathogenic bacteria and those with antimicrobial resistance found in wastewater mainly originate from excretory material from humans and animals [18]. Monitoring of pathogenic bacteria in wastewater could be used as an indicator of the health status of the people in the catchment area of the WWTP. Effective treatment of municipal wastewater is a basic need for controlling infectious diseases and other environmental and health hazards.

Water-scarce country Saudi Arabia encourages non-potable use of treated wastewater mainly for landscape and irrigation, and planning to achieve $100 \%$ reuse of treated wastewater by 2025 [19]. It is important to regularly perform the treated wastewater microbiology for assessment of potential risks pertaining to water reuse with an efficient metagenomics approach and should not be restricted to conventional microbiological quantification of coliform count or known pathogens. Since selective elimination or changes that occur in the population and composition of bacterial community during the biological process in the treatment plants and resulted bacterial diversity in the effluent provides an opportunity for the dissemination of these microorganisms and their resistance genes into the environment $[11,15,18]$. Several studies from Saudi Arabia have reported pharmaceutical, toxic, and heavy metal contaminants in the treated wastewater [20-22]. Picó et al. observed the accumulation of contaminants in soil and plant treated with wastewater in Al Hayer area [20]. However, limited studies have been conducted from Saudi Arabia to investigate the microbial flora of wastewater, and metagenomic characterization of wastewater studies are missing. In this study, we used a metagenomic approach to describe the microbial diversity, characterize microbial functions, and identify potential pathogenic taxa in pre-and post-treated domestic wastewater from a conventional sewage treatment plant in the city of Jeddah, the western region of Saudi Arabia.

\section{Materials and Methods}

\subsection{Sampling and Genomic DNA Extraction}

In this study, influent and effluent samples were collected in three replicates with a gap of $3 \mathrm{~h}$ from a conventional biological treatment plant using aerobic system and 
mechanical aeration located in the metropolitan city of Jeddah. The capacity of the WWTP was about $2000 \mathrm{~m}^{3} /$ day. Influent samples were collected from the raw sewage, and effluent samples were collected from the final treated water storage tank used for irrigation in clean sterilized containers. The samples were kept on ice during transportation to our laboratory at King Fahd Medical Research Center. The samples were stored at $-20{ }^{\circ} \mathrm{C}$ before processing for DNA extraction. Samples were centrifuged at $8000 \times g$ for $20 \mathrm{~min}$ at ambient temperature. Total genomic DNA was extracted from the 200-mg pelleted biomass of each replicate sample using DNeasy PowerSoil Kit (Qiagen, Hilden, Germany) following the manufacturer's instructions. The concentration of DNA was measured with a Qubit dsDNA BR assay using a Qubit fluorometer (Invitrogen, Carlsbad, CA, USA).

\subsection{Shotgun Sequencing and Data Analysis}

Extracted DNA from three replicates of each sample type was pooled in equal concentrations of $20 \mathrm{ng} / \mu \mathrm{L}$ to obtained homogenous representative total genomic DNA and processed as a one sample for shotgun sequencing. DNA libraries with $\sim 400$-bp insert size were prepared using Nextera XT DNA library preparation kit (Illumina, Inc., San Diego, California, USA). Sequencing was performed with $2 \times 300$ bp chemistry on a MiSeq platform (Illumina, Inc.), using a V3 cartridge from a 600-cycle kit (Illumina, Inc.) [23]. The raw sequence reads were uploaded to Metagenomic Rapid Annotations using Subsystems Technology (MG-RAST) and were analyzed using the default settings [24]. The classification of bacterial communities at different taxonomic levels from the metagenomes isolated from samples was performed by annotating the open reading frames (ORFs) against the NCBI reference sequence (RefSeq) database in MG-RAST. The identification of potential pathogenic taxa was further confirmed by using the tools of Kaiju, GOTTCHA2, and PATRIC that use protein-level, gene-independent signature-based metagenomic taxonomic classification, and Kraken 2 algorithm based on k-mers, respectively. For functional analysis, the ORFs were mapped to seed sub-system and KEGG Orthology (KO) databases. The de novo assemblies were prepared from high-quality reads using MetaSPAdes algorithms. The alpha diversity was performed with the Chao1 and Shannon diversity indices using the Calypso 8.84 server [25]. Sequencing data were deposited into the European Nucleotide Archive (ENA) under accession numbers SAMEA7130608 to SAMEA7130609.

\section{Results and Discussion}

\subsection{Microbial Diversity}

A massive amount of wastewater $\left(>300 \mathrm{~km}^{3}\right)$ is produced around the globe each year, and only about $60 \%$ is treated before being release into the aquatic environment [1]. Several studies have identified diverse microbial communities in the wastewater that could influence the microbial ecology of the connected ecosystem $[6,26,27]$. Especially of the expansion in use of treated wastewater in the semi-arid climate country like Saudi Arabia for irrigation and industrial use makes it essential to characterize the microbial quality of these conventionally treated water sources [19]. In agreement with previous studies, our metagenomic analysis revealed complex microbial communities in the domestic sewage samples collected from a conventional sewage treatment plant in the coastal city of Jeddah. In rarefaction curves, both the samples attended saturation plateau (Figure 1A). Chao1 analysis demonstrated a decrease estimated richness of species in effluent compared to influent (Figure 1B). The Shannon index analysis revealed increased diversity in effluent compared to influent (Figure 1C). 

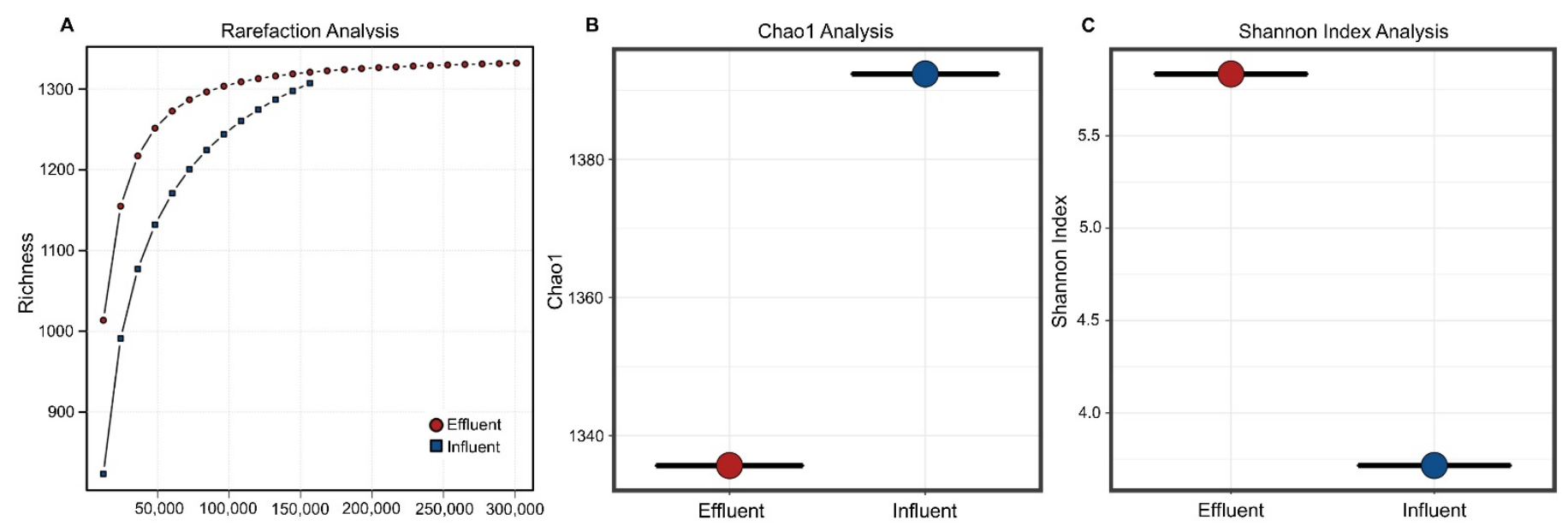

Figure 1. Diversity analysis of the domestic sewage metagenomes sequence reads. (A) Rarefaction analysis of influent and effluent samples, (B) chao1 index, and (C) Shannon diversity index.

\subsection{Bacteria}

Bacteria were the prevalent type of microbe in both influent and effluent samples (influent $=98.9 \%$, effluent $=98.1 \%$ ), whereas archaea and virus were each detected at less than $1 \%$ abundance. In a previous study from China, a comparable concentration of bacteria $(95.1 \%)$ was found in sewage treatment plant influent [26]. We found 33 phyla in the studied samples, including 28 bacteria and five archaeal phyla. Among those, 25 bacterial phyla and four archaeal phyla were common in both influent and effluent samples. Moreover, 241 families, 583 genera, and 1417 species of bacteria were retrieved from both samples. Among archaea, 29 families, 60 genera, and 88 species were identified. In addition, 150 viruses, mainly bacteriophages, were identified in influent and 240 in effluent samples. Domestic sewage is mainly comprised of microbial flora of human and animal wastes, vegetables, food, and soil. Diverse bacteria comprising influent, treatment process without membrane bioreactor and tertiary treatment, and the local environmental conditions of relatively high temperature may result the high diversity of bacterial community in the effluent of conventional biologically treated wastewater [2]. Moreover, bacteria play a crucial role in wastewater treatment [28]. Similarly, Giwa et al. detected more diverse bacteria and measurable concentrations of archaea and viruses in the effluent compared with the influent in a metagenomic analysis of samples from a biological WWTP [26].

The most abundant phylum in the sewage samples was Proteobacteria followed by Bacteroidetes, Firmicutes, and Actinobacteria (Figure 2A). The relative abundance of $18 \mathrm{mi}-$ nor phyla was less than $1 \%$ in both samples, whereas Fibrobacteres, Dictyoglomi, and Candidatus Poribacteria were uniquely identified in the effluent metagenome. Proteobacteria accounted for $85.9 \%$ and $63.8 \%$ of the classified sequences in influent and effluent samples, respectively (Figure 2A). Recently, a study of the global diversity of bacterial communities in 269 WWTPs showed the predominance of Proteobacteria in wastewater [3] and found that this phylum plays a broad role in organic matter degradation and nutrient cycling [2]. In the current study, phylotypes belonging to the $\varepsilon$-proteobacteria class dominated Proteobacteria in the influent $(63.02 \%)$ but sharply decreased to $0.6 \%$ in the effluent. $\beta$-proteobacteria were more abundant in the effluent (39.6\%) compared with the influent $(4.8 \%)$, whereas $\gamma$-proteobacteria were detected at a relatively high abundance in both samples (influent $=10.1 \%$, effluent $=14.8 \%$ ). The results showing the Proteobacteria community markedly changed between the raw and treated wastewater. However, a detailed comparison between the effluent and influent wastewater communities identified shared taxa between the two types of samples. A positive correlation has been previously identified between the abundance of $\varepsilon$-proteobacteria and occurrence of antibiotics contamination like penicillins, tetracycline, quinolones, sulfonamides, and triclosan in the influent 
of urban wastewater and was negatively correlated with the abundance of $\beta$-proteobacteria, and Firmicutes [29]. In comparison, $\beta$-proteobacteria observed abundantly in the treated wastewater irrespective of the seasonal temperature effect and mainly responsible for organic and nutrient removal [30].
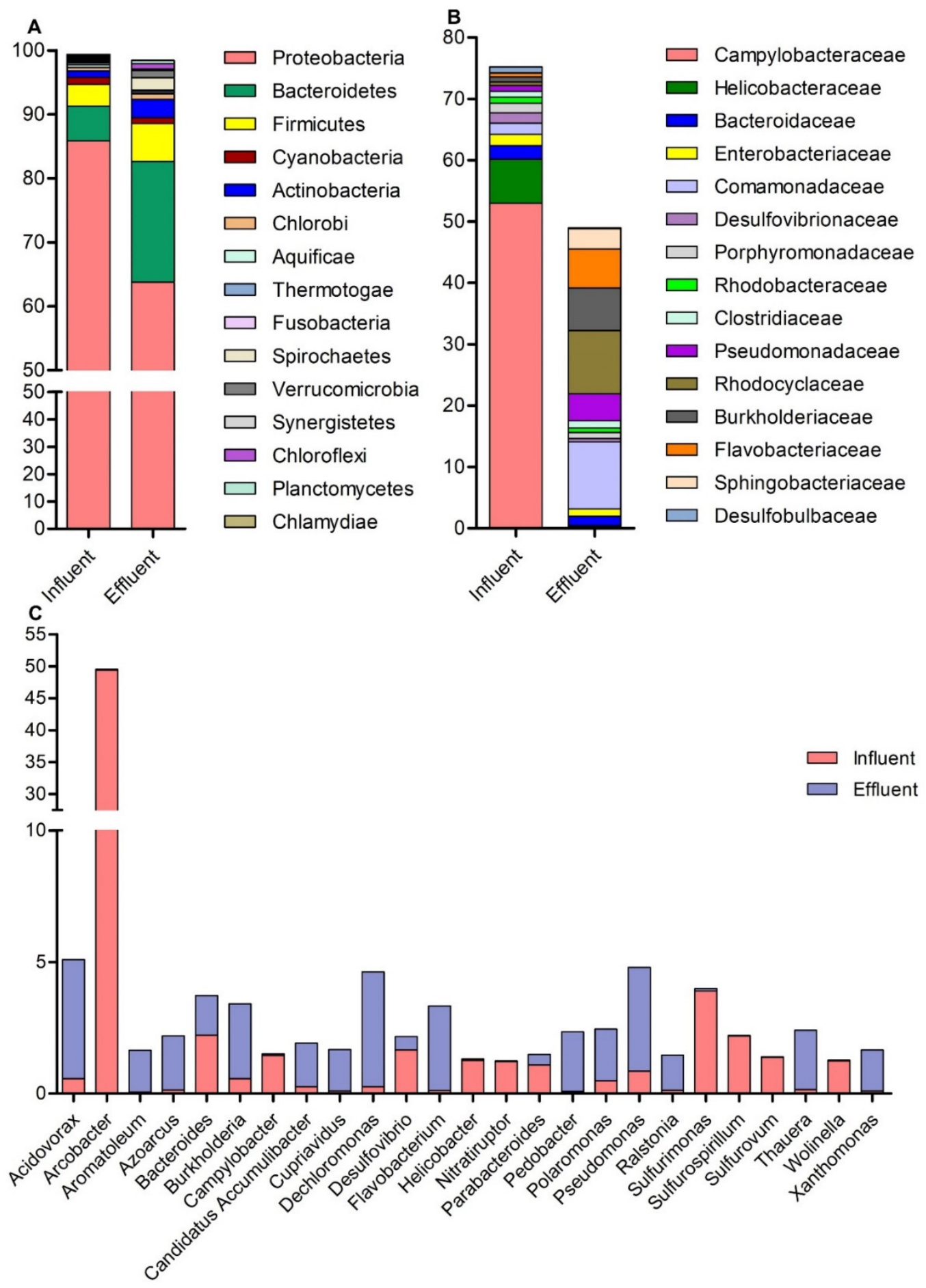

Figure 2. Taxonomic analysis of bacterial communities in the influent and effluent metagenomes. Percent abundance of the relatively dominant $(\mathbf{A})$ phyla, (B) families, and (C) genera. The $\mathrm{x}$-axis shows taxa, and the $\mathrm{y}$-axis indicates abundance in percentage. The relative abundance was calculated by normalizing the sequence reads of each bacteria taxon to the total number of bacteria associated sequences reads in the respective metagenome. 
Bacteroidetes increased to $18.9 \%$ in the effluent from $5.4 \%$ in the influent and were mainly represented by the classes Flavobacteria, Sphingobacteria, and Cytophagia. Taxa from another class, Bacteroidia, were found at a relatively higher abundance in the influent $(4.18 \%)$ compared with the effluent $(2.98 \%)$. The Clostridia class dominated Firmicutes (influent $=1.9 \%$, effluent $=3.2 \%$ ). Bacteria from the phyla Firmicutes and Bacteroidetes have been previously reported to compose the predominant community in human stool samples [31,32], but they were relatively less abundant than Proteobacteria in our sewage samples. The data suggest that the bacterial community of sewage influent mainly had a nonfecal origin, as previously observed from a sewage analysis in US cities [33]. Microbes in the human gut are mainly anaerobes and likely have low survival rates after being discharged into an aerobic sewage environment. Meanwhile, the mixing of fecal and nonfecal bacteria leads to a novel microbial community composition in sewage [27]. The variation observed in relative abundance of Bacteroidetes in several studies between influents (5.1-15.7\%) and effluents (2.4-12.5\%) can probably be attributed to types of wastewater processed, modifications of the biological treatment condition as well as of variation in environmental factors in different geographical regions [34]. For example, Proteobacteria most abundantly identified in aerobic, whereas Bacteroidetes taxa were abundantly found in anaerobic treatment process [35].

At the family level, the most dominant families differed between the influent and effluent samples. In influent, 12 families were identified at $\geq 1 \%$ relative abundance and accounted for $75.5 \%$ of the total sequence reads. Families of Campylobacteraceae (53\%) and Helicobacteraceae (7.2\%) from $\varepsilon$-proteobacteria were dominant in influent (Figure 2B). Gram-negative bacteria from the families Enterobacteriaceae and Pseudomonadaceae and sulfate-reducing bacterial families Desulfovibrionaceae and Desulfobulbaceae were detected in influent at a range of $1 \%$ to $2 \%$. The human gut-associated family Bacteroidaceae was found at a relatively higher abundance in influent $(2.2 \%)$ compared with effluent (1.5\%), as previously reported [33]. In effluent, 25 families were identified as having $\geq 1 \%$ abundance and accounted for $68.9 \%$ of total sequence reads. Families of Comamonadaceae (10.9\%), Rhodocyclaceae (10.3\%), and Burkholderiaceae $(6.9 \%)$ from $\beta$-proteobacteria and Flavobacteriaceae (6.4\%) from phylum Bacteroidetes were dominant in effluent (Figure 2B). The sulfate-reducing bacterial families had less than $1 \%$ abundance, and Enterobacteriaceae was detected at $1.2 \%$ in effluent. The relative abundance of Pseudomonadaceae increased to $4.4 \%$ in effluent compared with $1.0 \%$ in influent. Consistent with our findings, Gonzalez-Martinez et al. identified the families of Campylobacteraceae, Bacteroidaceae, and Comamonadaceae at high concentrations in 10 different wastewater treatment systems (WWTSs) and their influents [36]. Previously, Rhodocyclaceae and Comamonadaceae were described as the core families in wastewater treatment activated sludge systems responsible for denitrification and aromatic compound degradation [37].

A higher number of genera were identified in effluent compared with influent. Among the 583 genera identified in the current study, 171 genera were uniquely found in effluent and 412 genera in influent were commonly also found in effluent. Consistent with previous studies, variation in relative abundance of different genera was observed between influent and effluent samples [26]. In influent, 11 genera were identified as having $\geq 1 \%$ abundance and represented $65.9 \%$ of the total genera. Genus Arcobacter from Campylobacteraceae was predominantly found in the influent (49.39\%) and included two dominant species, Arcobacter butzleri (35.38\%) and Arcobacter nitrofigilis (14.01\%, Figure 2C). Other relatively dominant genera included Sulfurimonas (3.9\%), Bacteroides (2.22\%), Sulfurospirillum (2.19\%), Desulfovibrio (1.7\%), Campylobacter (1.4\%), and Helicobacter (1.3\%), which had less than $1 \%$ abundance in effluent, with the exception of Bacteroides (1.52\%, Figure 2C). Previously, Arcobacter was reported to be the most dominant bacteria in influent and supported by metagenomic analysis of wastewater samples from multiple countries, including Canada, China, Germany, Saudi Arabia, and the United States [3,11,38,39]. Bacteria from this taxon have been associated with both humans and animal infection and can cause gastroenteritis, mastitis, and abortion in livestock [40]. Arcobacter along with Pseudomonas, Acinetobacter, 
Bacteroides, Aeromonas, and Trichococcus was identified as a consistent genus in sewage influent, which are considered residents of the sewer infrastructure [16,36]. Among the core genera described, Clostridium and Bacteroides are consistent genera in the human gut microbiota, which suggests that human gut bacteria are part of the core genera of domestic wastewater [41].

In effluent, 15 genera were found to have an abundance of more than $1 \%$ and represented $36.7 \%$ of the total genera. Genera of Acidovorax (4.52\%), Dechloromonas (4.37\%), Pseudomonas (3.95\%), Flavobacterium (3.21\%), and Burkholderia (2.84\%) were found at relatively higher abundance in effluent (Figure 2C). Species of Acidovorax and Dechloromonas have been reported from WWTSs capable of aerobic heterotrophic growth and of anaerobic growth through denitrification [42,43]. Moreover, the sulfate-reducing bacteria (i.e., Sulfurospirillum, Desulfomicrobium, Desulfuromonas, Desulfovibrio, Desulfobacter, and Thiobacillus) are commonly found in WWTSs and other aquatic environments [44]. Metagenomic analysis provided us with broad profiles of bacterial pathogens in wastewater. Li et al. identified 113 pathogenic bacterial species from influent, effluent, and activated sludge samples from a sewage treatment plant [45]. In the current study, relative increases in the diversity of known pathogenic and opportunistic bacteria were found in effluent. Among the 87 pathogenic/opportunistic bacteria identified (representing 47 distinct genera), 62 were common to influent and effluent samples, whereas 24 were unique to effluent. Among the ESKAPE pathogens Enterococcus faecium, Klebsiella pneumoniae, Acinetobacter baumannii, and Pseudomonas aeruginosa were commonly found in both types of samples based on metagenomics (Table 1). However, the relative abundance of the pathogenic bacteria was $<0.1 \%$ in the studied samples, with the exception of Pseudomonas aeruginosa, which was detected at a relatively higher abundance in effluent (1.19\%). Also, Al-Jassim et al. reported Pseudomonas spp. from a conventional wastewater treatment plant in Saudi Arabia using 16S amplicon sequencing and further revealed that Pseudomonas aeruginosa was mainly found in the influent and non-chlorinated effluent samples using culture-dependent method [11]. In the influent, taxa from the pathogenic genera of Bacteroides, Campylobacter, and Helicobacter had $>1 \%$ abundance, and Campylobacter and Helicobacter were substantially decreased in effluent $(<0.1 \%$ abundance). Burkholderia were identified as having $2.84 \%$ abundance in effluent compared with $0.57 \%$ in influent (Table 1 ). In previous studies from conventional wastewater treatment plant, the bacterial pathogens A. baumannii, K. pneumoniae, and E. coli were often detected in sewage by both molecular- [26] and culture-dependent methods [18]. However, the identification of diverse pathogens in the effluent samples suggests that the sedimentation procedure does not entirely prevent microbiota from being transferred into effluent [26].

\subsection{Archaea}

Archaea were identified as having the same relative abundance $(0.6 \%)$ in the metagenomes of both samples, but variations were noted in the distribution of taxa and their abundance between influent and effluent. The archaeal sequence reads were dominantly aligned to Euryarchaeota $(\geq 90 \%)$ in both samples, whereas Crenarchaeota increased to $8.0 \%$ in effluent from 2.1\% in influent (Figure 3A). Similarly, Qin et al. reported that Euryarchaeota was dominant, followed by Crenarchaeota in samples from WWTPs [46]. The archaea community included 20 methanogenic genera that overall represented $85.3 \%$ of archaeaassociated sequence reads in influent and $60.2 \%$ in effluent; they were taxonomically classified mainly to Methanoregula, Methanosarcina, Methanococcoides, Methanospirillum, Methanococcus, Methanoculleus, and Methanocaldococcus (Figure 3B). In addition, the presence of methanogenic archaea, including genera of Thermococcus, Pyrococcus, and Archaeoglobus, was identified with more than $1 \%$ abundance in both influent and effluent metagenomes (Figure 3B). Methanogens are the most diverse groups of archaea and the focus of research because of their substantial contribution to methane emissions globally, as well as their role in wastewater treatment. Previously, families of Methanosaetaceae and Methanosarcinaceae were reported to be the predominant archaeal methanogens among the archaeal 
population in WWTSs [14]. These finding showed that archaea participate in the biodegradation process [46].

Table 1. Percentage relative abundance of potential pathogens at genus and species levels revealed by shotgun sequencing of the influent and effluent metagenomes.

\begin{tabular}{cccc}
\hline Genus & Species & Influent & Effluent \\
\hline Acinetobacter & Acinetobacter baumannii & 0.15 & 0.11 \\
Azotobacter & Azotobacter vinelandii & 0.02 & 0.37 \\
Bacteroides & Bacteroides fragilis & 0.40 & 0.24 \\
Bordetella & Bordetella bronchiseptica & 0.05 & 0.26 \\
Burkholderia & Burkholderia pseudomallei & 0.10 & 0.41 \\
Campylobacter & Campylobacter jejuni & 0.52 & 0.01 \\
Campylobacter & Campylobacter fetus & 0.38 & 0.01 \\
Clostridium & Clostridium botulinum & 0.05 & 0.12 \\
Enterococcus & Enterococcus faecium & 0.15 & 0.04 \\
Escherichia & Escherichia coli & 0.55 & 0.20 \\
Fusobacterium & Fusobacterium nucleatum & 0.15 & 0.04 \\
Helicobacter & Helicobacter pylori & 0.81 & 0.01 \\
Klebsiella & Klebsiella pneumoniae & 0.02 & 0.12 \\
Leptospira & Leptospira interrogans & 0.02 & 0.12 \\
Porphyromonas & Porphyromonas gingivalis & 0.18 & 0.19 \\
Pseudomonas & Pseudomonas aeruginosa & 0.30 & 1.19 \\
Stenotrophomonas & Stenotrophomonas maltophilia & 0.02 & 0.51 \\
Treponema & Treponema denticola & 0.01 & 0.40 \\
Vibrio & Vibrio parahaemolyticus & 0.33 & 0.03 \\
Vibrio & Vibrio cholerae & 0.11 & 0.08 \\
\hline
\end{tabular}
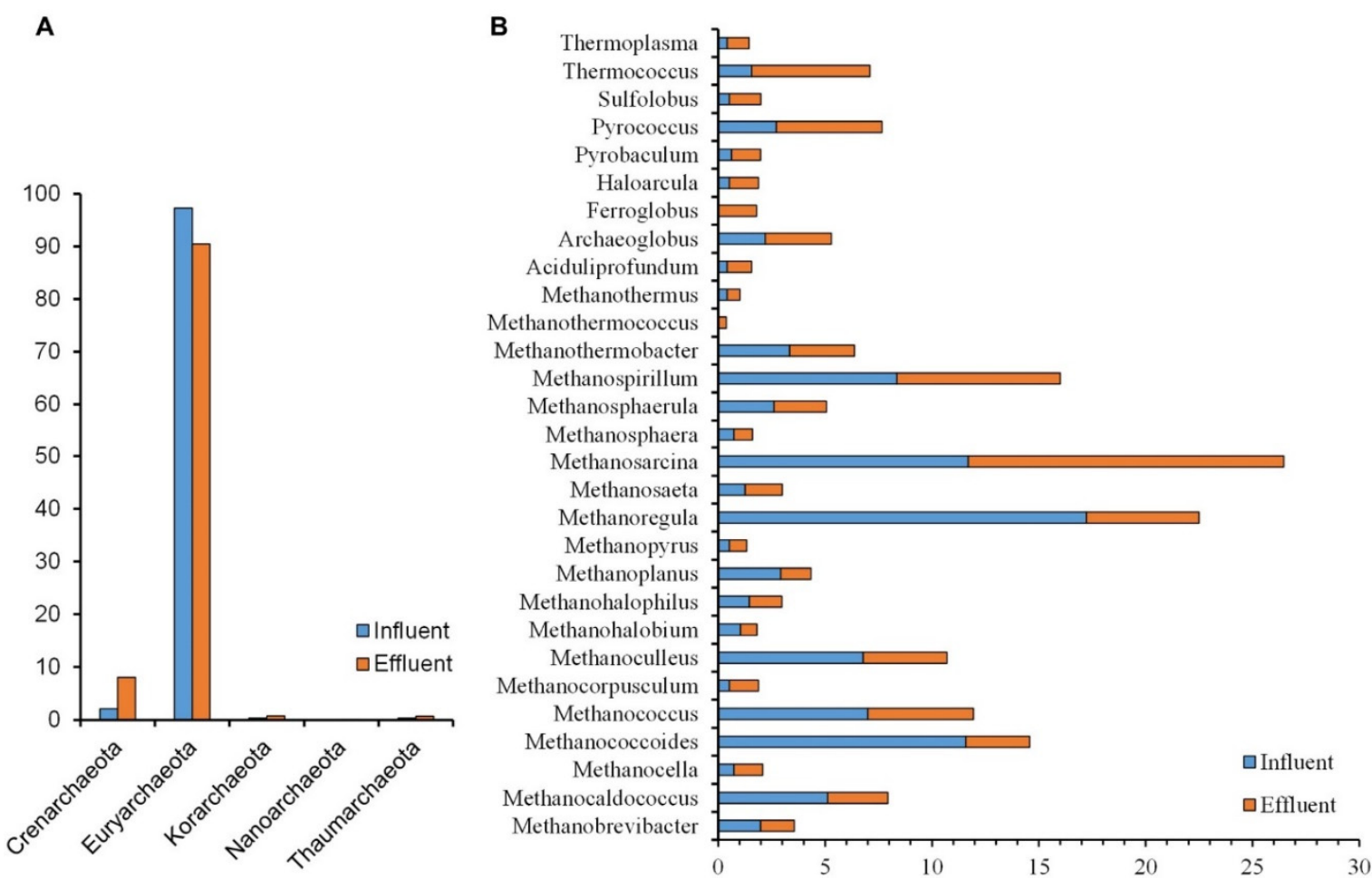

Figure 3. Taxonomic analysis of archaea associated sequence reads in the influent and effluent samples. Percent relative abundance of (A) phyla, and (B) genera identified methanogenic or detected in relatively higher abundance. The relative abundance was calculated by normalizing the sequence reads of each archaea taxon to the total number of archaea associated sequences reads in the respective metagenome. 


\subsection{Virus}

Bacteria are the main microorganisms in wastewater, and bacteriophages regulate the microbial community composition in wastewater system [47]. In the current study, the viromes was analyzed based on the metagenomes using the RefSeq database. Only $0.3 \%$ sequence reads in influent and $0.6 \%$ in effluent were related to viral genotypes, and they were taxonomically classified into 10 families. Around $5 \%$ of identified viruses could not be classified to existing viral families. The most frequent families of viruses found were Myoviridae (influent $=32.9 \%$, effluent $=43.9 \%$ ), Siphoviridae $($ influent $=32.3 \%$, effluent $=25.6 \%$, and Podoviridae (influent $=25.9 \%$, effluent $=20.5 \%$ ). These families include bacteriophage viruses and accounted for $\geq 90 \%$ of the virus sequence reads. Among the 76 Myoviridaeassociated phages, Burkholderia, Prochlorococcus, Enterobacteria, and Synechococcus phages were detected at relatively higher abundances (Figure 4). From Siphoviridae, 105 phages were detected, including Pseudomonas, Flavobacterium, Stenotrophomonas, and Mycobacterium phages, whereas Podoviridae was represented by 58 phages, including Bordetella, Enterobacteria, and Pseudomonas phages, which were relatively more abundant (Figure 4). Families of Poxviridae and Adenoviridae that include potential human pathogens were identified at $\leq 0.1 \%$ abundance in both types of samples. The lytic ssDNA viruses' family Microviridae was identified uniquely in effluent $(0.3 \%)$. Inconsistencies have been observed with regard to the abundance of viruses in wastewater systems. For example, in metagenomic detection of pathogens from a sewage treatment plant, Giwa et al. identified viruses at a relatively high abundance of $7 \%$ in the effluent [26]. In contrast, another study retrieved a minute concentration of viruses in wastewater [48]. Bacteriophages have been identified as the predominant members of the viral microbiomes studied [26,49]. They influence microbial communities through interactions with their specific bacterial hosts. We found that bacteriophages dominate virus-associated sequences in sewage metagenomes [49]. Metagenomic analysis in this study does not represent a complete profile of viruses' biodiversity and is considered a limitation of this study. Since total genomic DNA extracted from pellets of the centrifuged samples were used for shotgun sequencing. No viruses' specific protocols were adopted to get complete coverage of DNA and RNA viruses in the studied samples. However, the finding of this study is consistent with previous studies that reported bacteriophages predominantly in the wastewater samples [26].

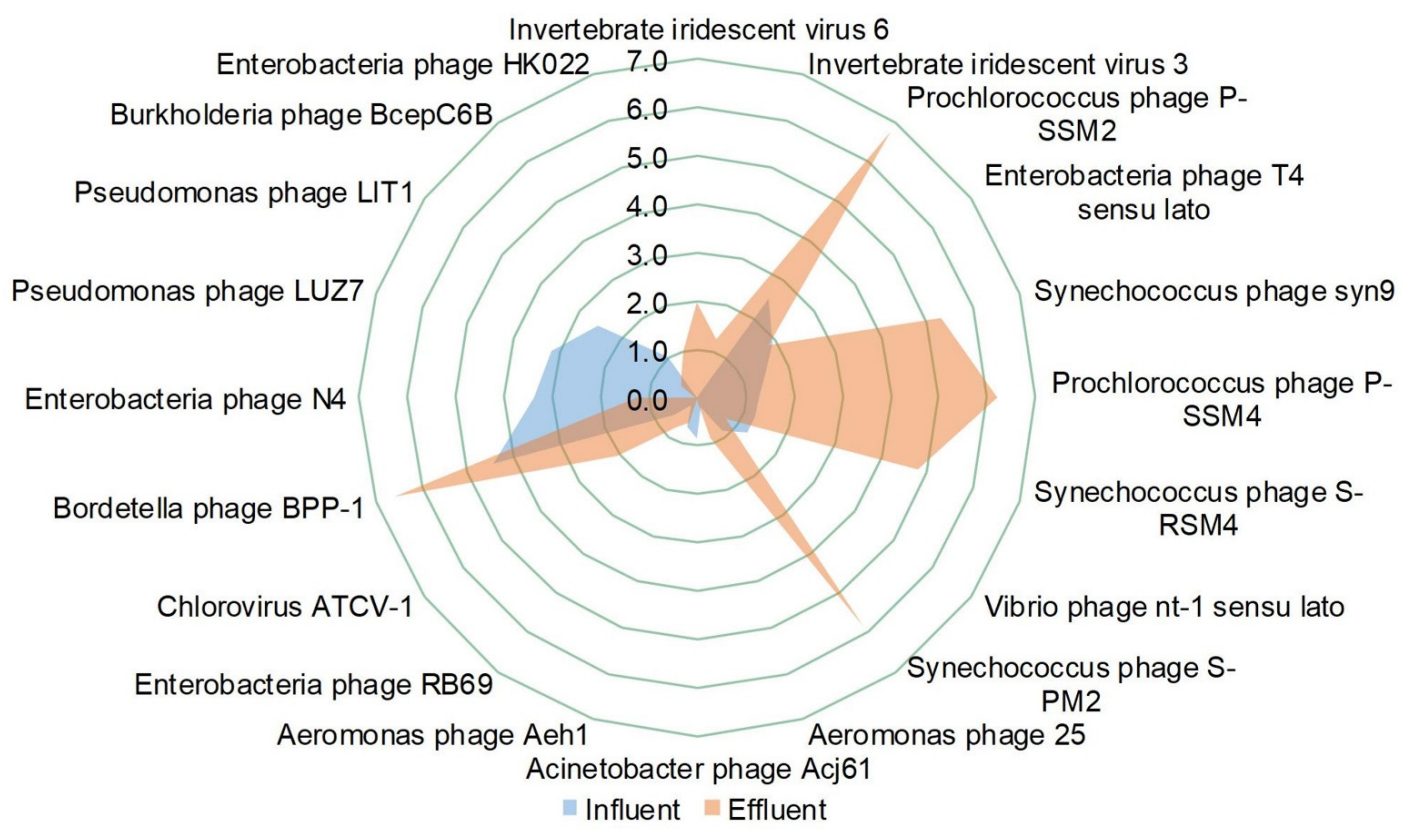

Figure 4. Diversity in percentage relative abundance of the viral taxonomy in the influent and effluent samples. The relative abundance was calculated by normalizing the sequence reads of each virus taxon to the total number of virus-associated sequences reads in the respective metagenome. 


\subsection{Metagenomes and Function Analysis}

A total of 176,540 sequence reads containing $54,668,916$ bp were obtained from influent, and 358,528 sequence reads containing 112,299,165 bp were obtained from effluent. Dereplication identified 6997 sequences as artificial duplicate reads in influent and 1036 sequences in effluent sample. Of the sequences tested, $5.8 \%$ in influent and $1.5 \%$ in effluent failed to pass the quality control pipeline. Mean $\mathrm{G}+\mathrm{C}$ content was $37 \pm 13 \%$ in influent and $55 \pm 13 \%$ in effluent. The mean length of reads was $310 \pm 108 \mathrm{bp}$ for influent and $313 \pm 75 \mathrm{bp}$ for effluent. The total number of predicted protein features was 90,271 in influent and 331,250 in effluent. The predicted rRNA features were 729 in influent and 1515 in effluent.

A significant proportion of both metagenomes was associated with housekeeping functions. The genes for amino acids and derivatives, protein metabolism, carbohydrates, nucleosides and nucleotides, respiration, cell wall and capsule, cofactors, vitamins, prosthetic groups, pigments, virulence, disease, and defense were present at relatively high abundance (3.4-12.9\%) in both samples (Figure 5A). SEED subsystem classification suggested that pathways related to resistance to antibiotics and toxic compounds, gram-negative cell wall components, flagellar motility in prokaryotes, and inorganic sulfur assimilation were higher in influent compared to effluent sample (Figure 5B). Genes for RNA processing and modification, DNA repair, protein degradation, and capsular and extracellular polysaccharides were present at relatively higher abundance in effluent than influent (Figure 5B). The results from this study are consistent with the reported occurrence of a large core of genes in wastewater that are essential for microbial cellular and community functions $[7,28]$.

Genes related to cobalt-zinc-cadmium resistance $(1.9 \%)$ and multidrug resistance efflux pumps (2.4\%) were relatively abundant in influent compared with effluent $(>1 \%)$. Moreover, $\beta$-lactamase, aminoglycoside adenylyltransferases, and methicillin resistance genes were detected in both samples at less than $1 \%$ abundance. Domestic sewage is considered a potential source of antimicrobial resistance genes. Charmaine et al. identified a variety of antimicrobial resistance genes causing multidrug resistance to quinolone, $\beta$-lactam, rifamycin, chloramphenicol, bacitracin aminoglycoside, sulfonamide, tetracycline, and vancomycin in a metagenomic study of municipal WWTPs [12]. The diversity of antimicrobial resistance genes in wastewater depends on the type of waste under processing. From an environmental health perspective, it is crucial to appropriately treat raw sewage because it may enter the connected aquatic ecosystem.

Similarly, in the KO database, metabolism-associated genes were found with more than $50 \%$ relative abundance, followed by genes related to genetic information processing, environmental information processing, and cellular processes (Figure 6A). Further analysis at the subcategory level revealed that pathways for alanine, aspartate, and glutamate metabolism [PATH:ko00250] and the cysteine and methionine metabolism [PATH:ko00270] were detected at a relatively higher abundance in influent $(9.4 \%$ and $5.3 \%)$ compared with effluent (3.5\% and 2.2\%), respectively (Figure 6B). ABC transporters [PATH:ko02010] and bacterial secretion system [PATH:ko03070] pathways from the membrane transport category were identified at relatively higher abundance in effluent $(6.6 \%$ and $2.2 \%)$ compared with influent $(3.2 \%$ and $1.7 \%$ ), respectively (Figure $6 \mathrm{~B}$ ). The genes related to pathways for glycolysis/gluconeogenesis [PATH:ko00010], bacterial chemotaxis [PATH:ko02030], flagellar assembly [PATH:ko02040], peptidoglycan biosynthesis [PATH:ko00550], and nitrogen metabolism [PATH:ko00910] were also detected at a relative abundance of $\geq 1 \%$ in both samples (Figure 6B). Previous metagenomic studies have also reported high proportions of these genes in wastewater. These genes are responsible for essential metabolic activities in microbial communities and are necessary in WWTSs [28]. In agreement with our findings, Sidhu et al. reported variation in the pre- and post-treated sewage [50]. They found genes for motility, DNA repair, protein metabolism, and respiration at significantly higher abundance in pretreated sewage, and genes related to amino acids and their derivatives, carbohydrate metabolism, fatty acids, and lipid metabolism were dominant in treated sewage samples [50]. 


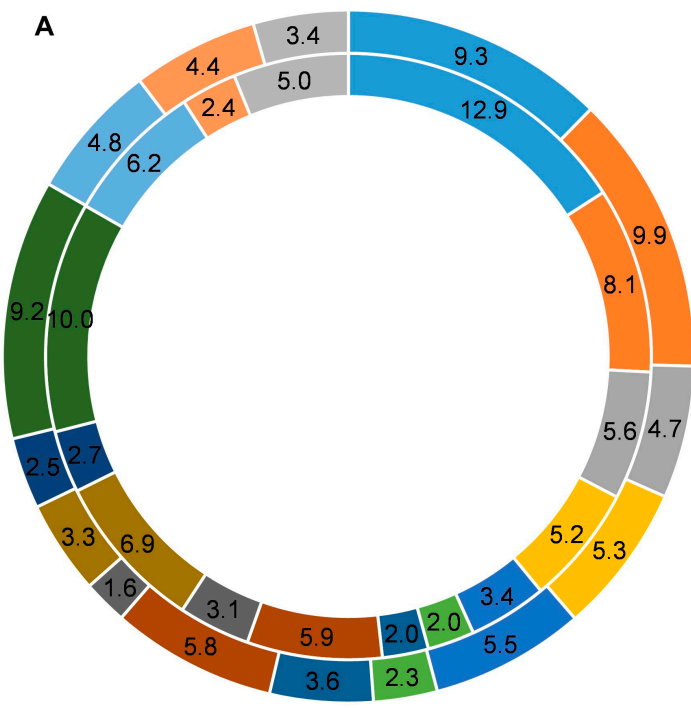

- Amino Acids and Derivatives

- Carbohydrates

- Cell Wall and Capsule

- Cofactors, Vitamins, Prosthetic Groups, Pigments

- DNA Metabolism

- Fatty Acids, Lipids, and Isoprenoids

- Membrane Transport

- Miscellaneous

- Motility and Chemotaxis

- Nucleosides and Nucleotides

- Phages, Prophages, Transposable elements, Plasmids

- Protein Metabolism

- Respiration

- RNA Metabolism

- Virulence, Disease and Defense

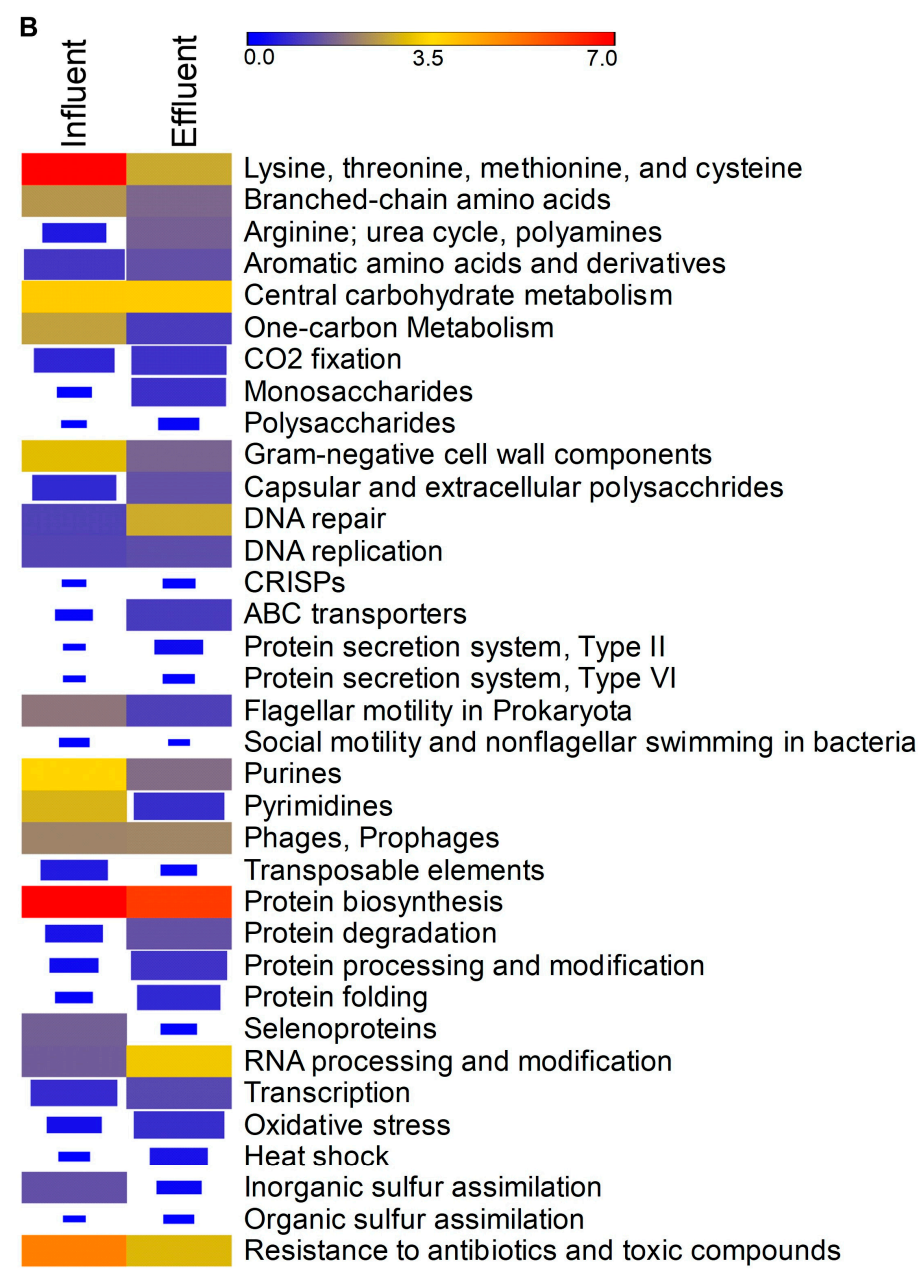

Figure 5. Functional analysis of the influent and effluent metagenomes. Percentage relative abundance of the dominant pathways identified by seed-subsystem mapping using MGRAST. (A) Abundance of the dominant pathways at level 1. Outer circle effluent and inner circle influent. (B) Abundance of the dominant pathways identified at sub-level 2. The size and color shade of the rectangle boxes are proportional to the relative abundance of the genes. 
A

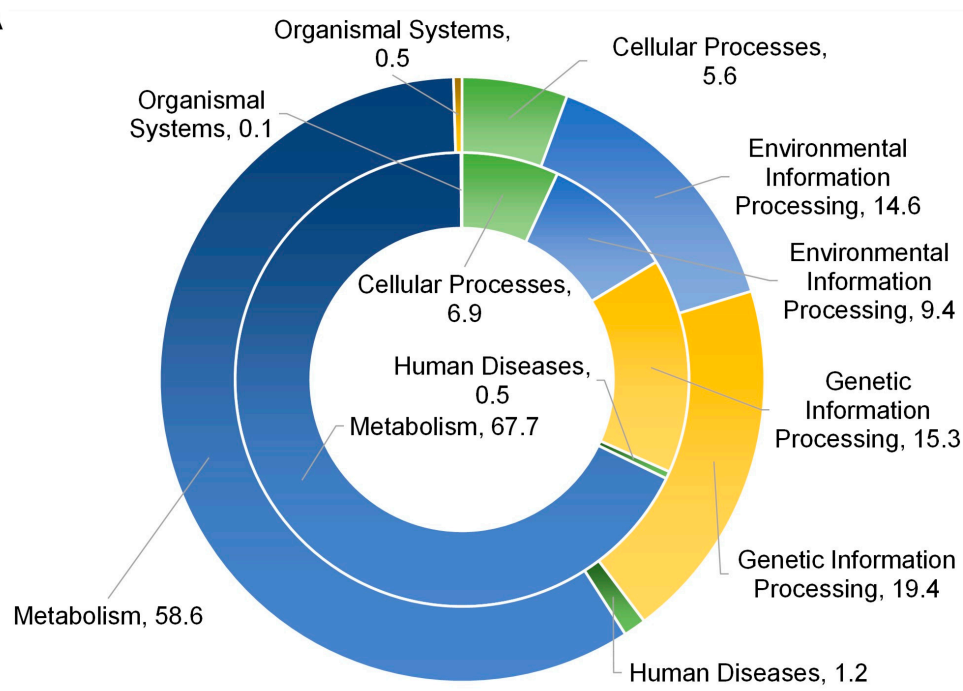

B

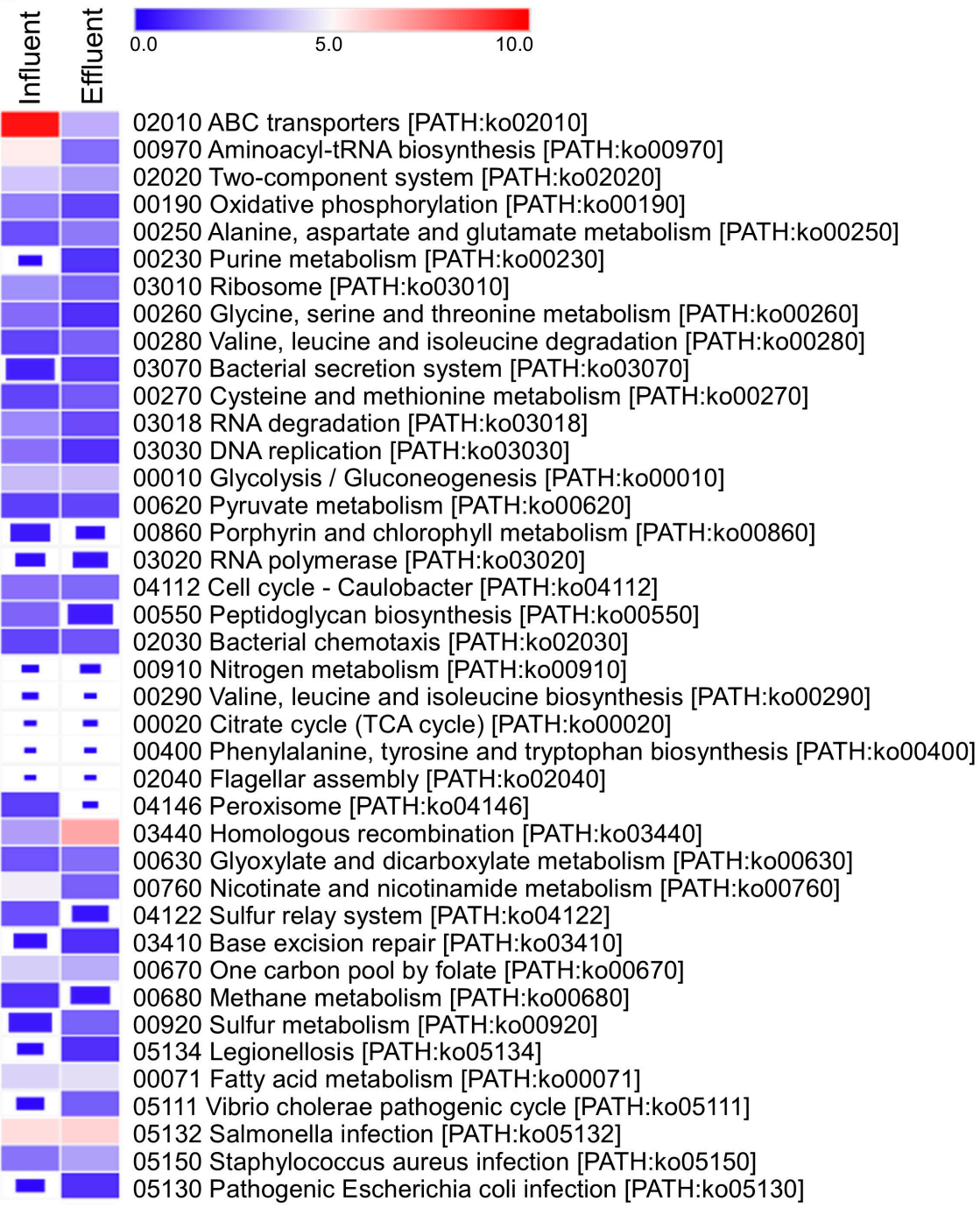

Figure 6. Functional analysis of the influent and effluent metagenomes. Percentage relative abundance of the dominant pathways identified by KEGG Orthology mapping. (A) Abundance of the dominant pathways at level 1. Inner ring represents influent and outer ring represent effluent (B) Abundance of the dominant pathways identified at sub-level. The size and color shade of the rectangle boxes are proportional to the relative abundance of the genes. 


\section{Conclusions}

This study provides a broad metagenomic analysis of the taxonomic and functional profile of microbial communities of influent and effluent from a conventional sewage treatment plant in Jeddah. The core bacterial community observed in this study showed similarity with the previously reported microflora of various conventional sewage treatment plants. Some of the microbial taxa were commonly detected in the influent and effluent samples, but the overall microbial community substantially changed in the effluent from influent at the lower taxonomic level. Although we found pathogenic bacteria, antimicrobial, and metal resistance genes in both influent and effluent samples, the levels were trivial, and associated environmental risks are most likely limited from its use in irrigation. The wastewater metagenomes carried mainly housekeeping genes along with functional pathways associated with the wastewater treatment process. Functional genes data obtained from metagenomic analysis can be used to enhance bioaugmentation for the improvement of contaminants degradation in wastewater treatment process. The data presented in this study is from one WWTP, and the low number of samples is the limitation of this study. Further research is recommended to investigate the microbial diversity and determine the distribution of pathogens and antimicrobial resistance genes over a broad scale and a long time in WWTPs from which effluent is used locally for irrigation and other non-potable use.

Author Contributions: Conceptualization: M.Y.; methodology: M.Y.; formal analysis: M.Y.; writingoriginal draft preparation: M.Y.; funding acquisition: M.Y. The author has read and agree to the published version of the manuscript.

Funding: This project was funded by the Deanship of Scientific Research (DSR) at King Abdulaziz University, Jeddah, under grant no. (G: 622-141-1439).

Institutional Review Board Statement: This study was approved by the ethical research committee of the Faculty of Medicine at King Abdulaziz University under the reference number (235-15).

Informed Consent Statement: Not applicable.

Data Availability Statement: Sequencing data is available from the European Nucleotide Archive (ENA) under accession numbers SAMEA7130608 to SAMEA7130609.

Acknowledgments: The author, acknowledges with thanks the Deanship of Scientific Research (DSR) for technical and financial support.

Conflicts of Interest: The authors declare no conflict of interest.

\section{References}

1. Mateo-Sagasta, J.; Raschid-Sally, L.; Thebo, A. Globel wastewater and sludge production, treatment and use. In Wastewater; Springer: Dordrecht, The Netherlands, 2015; pp. 15-38.

2. Nascimento, A.L.; Souza, A.J.; Andrade, P.A.M.; Andreote, F.D.; Coscione, A.R.; Oliveira, F.C.; Regitano, J.B. Sewage Sludge Microbial Structures and Relations to Their Sources, Treatments, and Chemical Attributes. Front. Microbiol. 2018, 9, 1462. [CrossRef] [PubMed]

3. Wu, L.; Ning, D.; Zhang, B.; Li, Y.; Zhang, P.; Shan, X.; Zhang, Q.; Brown, M.R.; Li, Z.; Van Nostrand, J.D.; et al. Global diversity and biogeography of bacterial communities in wastewater treatment plants. Nat. Microbiol. 2019, 4, 1183-1195. [CrossRef] [PubMed]

4. Chowdhary, P.; Raj, A.; Bharagava, R.N. Environmental pollution and health hazards from distillery wastewater and treatment approaches to combat the environmental threats: A review. Chemosphere 2018, 194, 229-246. [CrossRef] [PubMed]

5. Singh, A.K.; Chandra, R. Pollutants released from the pulp paper industry: Aquatic toxicity and their health hazards. Aquat. Toxicol. 2019, 211, 202-216. [CrossRef]

6. Al-Gheethi, A.A.; Efaq, A.N.; Bala, J.D.; Norli, I.; Abdel-Monem, M.O.; Kadir, M.O.A. Removal of pathogenic bacteria from sewage-treated effluent and biosolids for agricultural purposes. Appl. Water Sci. 2018, 8, 74. [CrossRef]

7. Delforno, T.P.; Lacerda, G.V., Jr.; Sierra-Garcia, I.N.; Okada, D.Y.; Macedo, T.Z.; Varesche, M.B.; Oliveira, V.M. Metagenomic analysis of the microbiome in three different bioreactor configurations applied to commercial laundry wastewater treatment. Sci. Total Environ. 2017, 587-588, 389-398. [CrossRef]

8. Ye, L.; Zhang, T. Pathogenic bacteria in sewage treatment plants as revealed by 454 pyrosequencing. Environ. Sci. Technol. 2011, 45,7173-7179. [CrossRef] 
9. Kim, Y.K.; Yoo, K.; Kim, M.S.; Han, I.; Lee, M.; Kang, B.R.; Lee, T.K.; Park, J. The capacity of wastewater treatment plants drives bacterial community structure and its assembly. Sci. Rep. 2019, 9, 14809. [CrossRef]

10. Zhang, T.; Shao, M.F.; Ye, L. 454 pyrosequencing reveals bacterial diversity of activated sludge from 14 sewage treatment plants. ISME J. 2012, 6, 1137-1147. [CrossRef]

11. Al-Jassim, N.; Ansari, M.I.; Harb, M.; Hong, P.Y. Removal of bacterial contaminants and antibiotic resistance genes by conventional wastewater treatment processes in Saudi Arabia: Is the treated wastewater safe to reuse for agricultural irrigation? Water Res. 2015, 73, 277-290. [CrossRef] [PubMed]

12. Ng, C.; Tan, B.; Jiang, X.T.; Gu, X.; Chen, H.; Schmitz, B.W.; Haller, L.; Charles, F.R.; Zhang, T.; Gin, K. Metagenomic and Resistome Analysis of a Full-Scale Municipal Wastewater Treatment Plant in Singapore Containing Membrane Bioreactors. Front. Microbiol. 2019, 10, 172. [CrossRef] [PubMed]

13. Tong, J.; Tang, A.; Wang, H.; Liu, X.; Huang, Z.; Wang, Z.; Zhang, J.; Wei, Y.; Su, Y.; Zhang, Y. Microbial community evolution and fate of antibiotic resistance genes along six different full-scale municipal wastewater treatment processes. Bioresour. Technol. 2019, 272, 489-500. [CrossRef] [PubMed]

14. Khan, M.A.; Patel, P.G.; Ganesh, A.G.; Rais, N.; Faheem, S.M.; Khan, S.T. Assessing Methanogenic Archaeal Community in Full Scale Anaerobic Sludge Digester Systems in Dubai, United Arab Emirates. Open Microbiol. J. 2018, 12, 123-134. [CrossRef] [PubMed]

15. Lu, X.; Zhang, X.X.; Wang, Z.; Huang, K.; Wang, Y.; Liang, W.; Tan, Y.; Liu, B.; Tang, J. Bacterial pathogens and community composition in advanced sewage treatment systems revealed by metagenomics analysis based on high-throughput sequencing. PLoS ONE 2015, 10, e0125549. [CrossRef] [PubMed]

16. Vandewalle, J.L.; Goetz, G.W.; Huse, S.M.; Morrison, H.G.; Sogin, M.L.; Hoffmann, R.G.; Yan, K.; McLellan, S.L. Acinetobacter, Aeromonas and Trichococcus populations dominate the microbial community within urban sewer infrastructure. Environ. Microbiol. 2012, 14, 2538-2552. [CrossRef]

17. Shannon, K.E.; Lee, D.Y.; Trevors, J.T.; Beaudette, L.A. Application of real-time quantitative PCR for the detection of selected bacterial pathogens during municipal wastewater treatment. Sci. Total Environ. 2007, 382, 121-129. [CrossRef] [PubMed]

18. Elmund, G.K.; Allen, M.J.; Rice, E.W. Comparison of Escherichia coli, Total Coliform, and Fecal Coliform Populations as Indicators of Wastewater Treatment Efficiency. Water Environ. Res. 1999, 71, 332-339. [CrossRef]

19. Ouda, O.K.M. Treated wastewater use in Saudi Arabia: Challenges and initiatives. Int. J. Water Res. Dev. 2016, 32, 799-809. [CrossRef]

20. Pico, Y.; Alvarez-Ruiz, R.; Alfarhan, A.H.; El-Sheikh, M.A.; Alobaid, S.M.; Barcelo, D. Uptake and accumulation of emerging contaminants in soil and plant treated with wastewater under real-world environmental conditions in the Al Hayer area (Saudi Arabia). Sci. Total Environ. 2019, 652, 562-572. [CrossRef]

21. Al-Saleh, I.; Elkhatib, R.; Al-Rajoudi, T.; Al-Qudaihi, G. Assessing the concentration of phthalate esters (PAEs) and bisphenol A (BPA) and the genotoxic potential of treated wastewater (final effluent) in Saudi Arabia. Sci. Total Environ. 2017, 578, 440-451. [CrossRef] [PubMed]

22. Al Qarni, H.; Collier, P.; O'Keeffe, J.; Akunna, J. Investigating the removal of some pharmaceutical compounds in hospital wastewater treatment plants operating in Saudi Arabia. Environ. Sci. Pollut. Res. Int. 2016, 23, 13003-13014. [CrossRef] [PubMed]

23. Yasir, M.; Farman, M.; Shah, M.W.; Jiman-Fatani, A.A.; Othman, N.A.; Almasaudi, S.B.; Alawi, M.; Shakil, S.; Al-Abdullah, N.; Ismaeel, N.A.; et al. Genomic and antimicrobial resistance genes diversity in multidrug-resistant CTX-M-positive isolates of Escherichia coli at a health care facility in Jeddah. J. Infect. Public Health 2020, 13, 94-100. [CrossRef] [PubMed]

24. Meyer, F.; Paarmann, D.; D’Souza, M.; Olson, R.; Glass, E.M.; Kubal, M.; Paczian, T.; Rodriguez, A.; Stevens, R.; Wilke, A.; et al. The metagenomics RAST server-A public resource for the automatic phylogenetic and functional analysis of metagenomes. BMC Bioinform. 2008, 9, 386. [CrossRef]

25. Zakrzewski, M.; Proietti, C.; Ellis, J.J.; Hasan, S.; Brion, M.J.; Berger, B.; Krause, L. Calypso: A user-friendly web-server for mining and visualizing microbiome-environment interactions. Bioinformatics 2017, 33, 782-783. [CrossRef]

26. Giwa, A.S.; Ali, N.; Athar, M.A.; Wang, K. Dissecting microbial community structure in sewage treatment plant for pathogens detection using metagenomic sequencing technology. Arch. Microbiol. 2020, 202, 825-833. [CrossRef]

27. Shanks, O.C.; Newton, R.J.; Kelty, C.A.; Huse, S.M.; Sogin, M.L.; McLellan, S.L. Comparison of the microbial community structures of untreated wastewaters from different geographic locales. Appl. Environ. Microbiol. 2013, 79, 2906-2913. [CrossRef]

28. Yang, Y.; Wang, L.; Xiang, F.; Zhao, L.; Qiao, Z. Activated Sludge Microbial Community and Treatment Performance of Wastewater Treatment Plants in Industrial and Municipal Zones. Int. J. Environ. Res. Public Health 2020, 17, 436. [CrossRef]

29. Novo, A.; Andre, S.; Viana, P.; Nunes, O.C.; Manaia, C.M. Antibiotic resistance, antimicrobial residues and bacterial community composition in urban wastewater. Water Res. 2013, 47, 1875-1887. [CrossRef]

30. Cydzik-Kwiatkowska, A.; Zielinska, M. Bacterial communities in full-scale wastewater treatment systems. World J. Microbiol. Biotechnol. 2016, 32, 66. [CrossRef]

31. Yasir, M.; Angelakis, E.; Bibi, F.; Azhar, E.I.; Bachar, D.; Lagier, J.C.; Gaborit, B.; Hassan, A.M.; Jiman-Fatani, A.A.; Alshali, K.Z.; et al. Comparison of the gut microbiota of people in France and Saudi Arabia. Nutr. Diabetes 2015, 5, e153. [CrossRef] [PubMed] 
32. Angelakis, E.; Yasir, M.; Bachar, D.; Azhar, E.I.; Lagier, J.C.; Bibi, F.; Jiman-Fatani, A.A.; Alawi, M.; Bakarman, M.A.; Robert, C.; et al. Gut microbiome and dietary patterns in different Saudi populations and monkeys. Sci. Rep. 2016, 6, 32191. [CrossRef] [PubMed]

33. Newton, R.J.; McLellan, S.L.; Dila, D.K.; Vineis, J.H.; Morrison, H.G.; Eren, A.M.; Sogin, M.L. Sewage reflects the microbiomes of human populations. mBio 2015, 6, e02574. [CrossRef] [PubMed]

34. Shchegolkova, N.M.; Krasnov, G.S.; Belova, A.A.; Dmitriev, A.A.; Kharitonov, S.L.; Klimina, K.M.; Melnikova, N.V.; Kudryavtseva, A.V. Microbial Community Structure of Activated Sludge in Treatment Plants with Different Wastewater Compositions. Front. Microbiol. 2016, 7, 90. [CrossRef]

35. Hu, M.; Wang, X.; Wen, X.; Xia, Y. Microbial community structures in different wastewater treatment plants as revealed by 454-pyrosequencing analysis. Bioresour. Technol. 2012, 117, 72-79. [CrossRef]

36. Gonzalez-Martinez, A.; Rodriguez-Sanchez, A.; Lotti, T.; Garcia-Ruiz, M.J.; Osorio, F.; Gonzalez-Lopez, J.; van Loosdrecht, M.C. Comparison of bacterial communities of conventional and A-stage activated sludge systems. Sci. Rep. 2016, 6, 18786. [CrossRef]

37. Xu, D.; Liu, S.; Chen, Q.; Ni, J. Microbial community compositions in different functional zones of Carrousel oxidation ditch system for domestic wastewater treatment. AMB Express 2017, 7, 40. [CrossRef]

38. Webb, A.L.; Taboada, E.N.; Selinger, L.B.; Boras, V.F.; Inglis, G.D. Efficacy of wastewater treatment on Arcobacter butzleri density and strain diversity. Water Res. 2016, 105, 291-296. [CrossRef]

39. Gao, P.; Xu, W.; Sontag, P.; Li, X.; Xue, G.; Liu, T.; Sun, W. Correlating microbial community compositions with environmental factors in activated sludge from four full-scale municipal wastewater treatment plants in Shanghai, China. Appl. Microbiol. Biotechnol. 2016, 100, 4663-4673. [CrossRef]

40. Collado, L.; Figueras, M.J. Taxonomy, epidemiology, and clinical relevance of the genus Arcobacter. Clin. Microbiol. Rev. 2011, 24, 174-192. [CrossRef]

41. Walker, A.W.; Duncan, S.H.; Louis, P.; Flint, H.J. Phylogeny, culturing, and metagenomics of the human gut microbiota. Trends Microbiol. 2014, 22, 267-274. [CrossRef] [PubMed]

42. Heylen, K.; Lebbe, L.; De Vos, P. Acidovorax caeni sp. nov., a denitrifying species with genetically diverse isolates from activated sludge. Int. J. Syst. Evol. Microbiol. 2008, 58, 73-77. [CrossRef] [PubMed]

43. Xie, B.; Liu, B.; Yi, Y.; Yang, L.; Liang, D.; Zhu, Y.; Liu, H. Microbiological mechanism of the improved nitrogen and phosphorus removal by embedding microbial fuel cell in Anaerobic-Anoxic-Oxic wastewater treatment process. Bioresour. Technol. 2016, 207, 109-117. [CrossRef] [PubMed]

44. Zhang, B.; Xu, X.; Zhu, L. Structure and function of the microbial consortia of activated sludge in typical municipal wastewater treatment plants in winter. Sci. Rep. 2017, 7, 17930. [CrossRef]

45. Li, B.; Ju, F.; Cai, L.; Zhang, T. Profile and Fate of Bacterial Pathogens in Sewage Treatment Plants Revealed by High-Throughput Metagenomic Approach. Environ. Sci. Technol. 2015, 49, 10492-10502. [CrossRef]

46. Qin, H.; Ji, B.; Zhang, S.; Kong, Z. Study on the bacterial and archaeal community structure and diversity of activated sludge from three wastewater treatment plants. Mar. Pollut. Bull. 2018, 135, 801-807. [CrossRef]

47. Shapiro, O.H.; Kushmaro, A.; Brenner, A. Bacteriophage predation regulates microbial abundance and diversity in a full-scale bioreactor treating industrial wastewater. ISME J. 2010, 4, 327-336. [CrossRef]

48. Delforno, T.P.; Lacerda Junior, G.V.; Noronha, M.F.; Sakamoto, I.K.; Varesche, M.B.A.; Oliveira, V.M. Microbial diversity of a full-scale UASB reactor applied to poultry slaughterhouse wastewater treatment: Integration of 16S rRNA gene amplicon and shotgun metagenomic sequencing. MicrobiologyOpen 2017, 6. [CrossRef]

49. Gulino, K.; Rahman, J.; Badri, M.; Morton, J.; Bonneau, R.; Ghedin, E. Initial Mapping of the New York City Wastewater Virome. mSystems 2020, 5. [CrossRef]

50. Sidhu, C.; Vikram, S.; Pinnaka, A.K. Unraveling the Microbial Interactions and Metabolic Potentials in Pre- and Post-treated Sludge from a Wastewater Treatment Plant Using Metagenomic Studies. Front. Microbiol. 2017, 8, 1382. [CrossRef] 